\title{
Measurement of Bone Mineral Density in Children with Cerebral Palsy from an Ethical Issue to a Diagnostic Necessity
}

\author{
Jasmin S. Nurković ${ }^{D}$, ${ }^{1,2}$ Pavle Petković, ${ }^{2,3}$ Danijela Tiosavljević, ${ }^{4}$ and Radiša Vojinović ${ }^{2,3}$ \\ ${ }^{1}$ Center for Regeneration and Rehabilitation, Novi Pazar, Serbia \\ ${ }^{2}$ Radiology Department, Faculty of Medical Sciences, University of Kragujevac, Serbia \\ ${ }^{3}$ Radiology Department, Clinical Center Kragujevac, Serbia \\ ${ }^{4}$ Department of Humanities, Medical Faculty, University of Belgrade, Serbia
}

Correspondence should be addressed to Jasmin S. Nurković; jnurkovic@gmail.com

Received 14 June 2020; Revised 28 August 2020; Accepted 8 September 2020; Published 21 September 2020

Academic Editor: Danilo Sales Bocalini

Copyright (c) 2020 Jasmin S. Nurković et al. This is an open access article distributed under the Creative Commons Attribution License, which permits unrestricted use, distribution, and reproduction in any medium, provided the original work is properly cited.

Introduction. Due to concerns about cumulative radiation exposure in the pediatric population, it is not standard practice to perform dual-energy X-ray absorptiometry (DXA) analysis in the diagnostic process of musculoskeletal disorders, such as cerebral palsy (CP). This study aimed to evaluate the bone mineral density (BMD) in children with $\mathrm{CP}$ and the ethical justification of applying DXA analysis in these children. Material and Methods. In this monocentric retrospective analysis, data were collected from children and adolescents with $\mathrm{CP}$ who were treated for a primary illness for three years. A clinical examination, which included a DXA analysis, recommended by the multidisciplinary team, was performed. After applying inclusion and exclusion criteria, 60 scans remained for statistical analysis. BMD and Z-scores for the lumbar spine (LS), and hip right and left femoral neck (RFN and LFN, respectively), and total hip (TH) were recorded. Results. The average age of children with CP when DXA analysis was first performed was about 7 years. The BMD (mean \pm SD) at LS (LS-BMD) of all patients was $0.612 \pm 0.12$, at RFN $0.555 \pm 0.11$, at LFN $0.572 \pm 0.1$, and at TH (TH-BMD) $0.581 \pm 0.13$. The values of the $Z$-score (mean $\pm \mathrm{SD}$ ) at LS of all patients were $-2.5 \pm 0.22$, at RFN $-2.2 \pm 0.21$, at LFN $-2.25(\mathrm{SD}=0.2)$, and at $\mathrm{TH}-2.3(\mathrm{SD}=0.23)$. There was no statistical significance between age and gender; however, BMI, walking ability, fracture history, and pattern of $\mathrm{CP}$ had a significant impact on BMD and $Z$-score values of these children. Conclusion. The results of our study clearly indicate that children with $\mathrm{CP}$ have a higher risk of low BMD, osteoporosis, and bone fractures, which makes it ethically justifiable to perform the DXA analysis in these children.

\section{Introduction}

The current standard for measuring bone mineral density (BMD) is dual-energy X-ray absorptiometry (DXA), due to its availability, accuracy, ease of repetition, and patients' low $\mathrm{X}$-ray exposure [1]. Using DXA analysis in pediatric population is complex, because of the bone mineral density changes during the process of growth and development. Children have not achieved their final bone mineral density; thus, every obtained result needs to be compared to the average value for the same sex and age ( $Z$-score), which means that the results vary at different ages, unlike adults, whose measured BMD value is compared to one standard, an "ideal" value for a grown, mature person ( $T$ score) [2]. Children of the same age can differ in skeletal maturity, which further adds complexity to the interpretation of DXA results. In children who have musculoskeletal disorders, e.g., cerebral palsy (CP), DXA analysis becomes even more challenging $[3,4]$.

$\mathrm{CP}$ is a term used for describing abnormal motor development of central origin, and it is the most prominent neurological disorder that occurs in childhood and continues into adulthood [5]. In developed countries, the incidence of this disorder is about 2 per 1000 live births. $70-80 \%$ of cases have a prenatal, unknown cause, while a smaller percentage occurs due to labor complications and problems in the early neonatal period [6]. CP patients have lower life expectancy compared to the general population, especially when severe complications and comorbidities are present [7]. Children with CP face 
numerous complications during their development: gastroesophageal reflux, aspiration syndromes, respiratory infections, seizures, and muscle contractures. In addition, aging-associated diseases like atherosclerosis, osteoporosis, sarcopenia, osteoarthritis, and dementia are more pronounced and occur earlier in CP patients, due to their static lifestyle. It is known that bone fractures are not a direct cause of death; however, their influence on morbidity is high [8]; therefore, measuring BMD is an important diagnostic procedure $[9,10]$. For low BMD-related fracture risk, osteoporosis assessment, and therapeutic possibilities are less defined, compared to adult population. However, in the last years, there has been progress regarding diagnostics and diagnostic classification of reduced $\mathrm{BMD}$ in children. International Society of Clinical Densitometry (ISCD) defined parameters for osteoporosis in children in 2008 [11].

In children, osteoporosis diagnosis is based on two criteria: (1) the presence of low BMD with a $Z$-score lower than -2.0 and (2) presence of fracture history (long bones of the upper and lower extremities, compression fractures of the vertebrae) $[11,12]$. Certain researchers consider that the term "osteopenia" should be avoided in children and that referring to $Z$-score results between 0 and -2 as "low BMD" is more appropriate [11]. Risk factors for low BMD values in children with CP are low weight, anticonvulsive therapy, poor nutrition, and inadequate sun exposure [10-12]. The incidence of bone fractures in children with a severe form of CP is 7-9.7\% per year, with fractures of the lower extremity of the femur being the most common.

Every pediatric X-ray exam, especially in those with psychomotor development impairments, represents an ethical dilemma, and the benefit of a diagnostic or therapeutic procedure must outweigh the risks of the procedure itself [13]. Applying the principles of informed consent in pediatric healthcare involves consent by the parent/guardian, as well as the consent of a child older than 15. Consent should be the result of a continuous interactive communication between the health care providers, the child, and the parent/guardian. In the process of obtaining consent, health care providers are obliged to include the child in decision-making, according to its maturity and cognitive abilities, and provide the child, as well as the parent/guardian, with a form and amount of information that would be comprehensive and clear. Older children and adolescents, without cognitive deficits, have a right to independently consent to a suggested medical procedure, provided they are adequately informed about all the aspects of it by the health care provider. In the case of them declining the medical procedure, the health care provider is obliged to ask the patient's legal guardian for consent [13].

In case of DXA analysis, for spinal and femoral scanning, the effective radiation dose varies between $0.5 \mu \mathrm{Sv}$ and $15 \mu \mathrm{S}$ for adults, while, in children, these values are higher and can reach $20 \mu \mathrm{S}$ [14]. By comparison, the average effective dose acquired by each individual from natural sources is about $10 \mu \mathrm{S}$. The usual duration of a scan for cooperative children is about 1 minute for the lumbar spine and 5-7 minutes for the whole body $[10,14]$.

Numerous studies have shown that physical exercise can improve bone metabolism, increase BMD and BMC, provide good bone structure and strengthen bone mass [15-17]. Therefore, physical and kinesitherapy treatment, which is an integral part of the treatment of these children, is very important, both because of the stimulation of motor development and the improvement of BMD.

This study aimed to evaluate the BMD in children with $\mathrm{CP}$ and ethical justification of applying DXA analysis in these children. Our hypothesis was that the obtained data would show significantly low values of BMD and $Z$-score, which increases the risk of bone fractures and that it would highlight the need for an adequate treatment, which is aimed at damage prevention. Our results may favor the need for exercise and kinesiotherapy in children with $\mathrm{CP}$.

\section{Material and Methods}

2.1. Study Design and Population. The present study is a monocentric retrospective analysis. Data were collected from children and adolescents with CP who were treated for a primary illness in a Center for Regeneration and Rehabilitation at Novi Pazar, Serbia, during a three-year period, from March 2017 to March 2020. A detailed clinical and radiological examination, which included a DXA analysis, recommended by the multidisciplinary team, physiatrist, child neurologist, radiologist and pediatrician, was carried out prior to the start of physical treatment in these children. This study was approved by our local institutional review and ethical board. All patients/caregivers provided a written informed consent to participate. All of the investigations have been conducted according to the ethical principles suggested in the Declaration of Helsinki. Measures have been made to protect the privacy of research subjects and the confidentiality of their personal information.

During the course of three years, 70 children with $\mathrm{CP}$ were treated in our Center. 65 DXA scans were performed. In 5 children, the analysis could not be done due to poor compliance. The inclusion criteria were diagnosis of $\mathrm{CP}$, Caucasian ethnicity, age 3 to 18 years, and written informed consent to full medical examination from patients, when possible, or from their parents/caregivers. The exclusion criteria were diseases primarily involving bone metabolism or familial history of bone metabolism disorders; chronic diseases with stunted growth, e.g., renal failure; and corticosteroid or growth hormone medication. The exclusion criteria were evaluated on the basis of patient records, due to the retrospective design of the study; this represents an important limitation of our study. After applying inclusion and exclusion criteria, 60 scans remained for statistical analysis. In 2 cases, kidney disease was the reason for exclusion from this study, 3 patients had previously received corticosteroid or growth hormone medication (Figure 1).

The CP patterns were classified as hemiplegic, diplegia, triplegia, or quadriplegic, in accordance with the criteria of the Surveillance of Cerebral Palsy in Europe [18].

2.2. Anthropometry. In children who were able to stand, body length was assessed with a stadiometer $\left(\mathrm{SECA}^{\circledR}{ }^{\circledR}\right.$, model No. 213, Hamburg, Germany) in $0.1 \mathrm{~cm}$ increments. In children who were unable to stand, a retractable metal tape was used. 


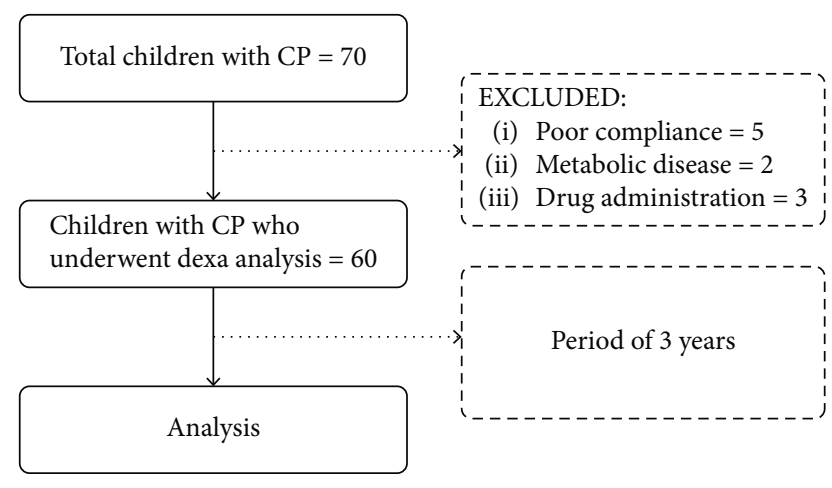

Figure 1: Participant flow diagram.

The body weight was measured by a digital scale in $0.1 \mathrm{~kg}$ increments. Body mass index (BMI) was calculated as a person's weight in kilograms divided by the square of their height in meters $\left(\mathrm{kg} / \mathrm{m}^{2}\right)$.

2.3. DXA Measurement and Data Acquisition. DXA scans were obtained using a HOLOGIC densitometer, model Discovery $\mathrm{Ci}$, by a single medical technician. Subjects' DXA scans over a 3-year period were utilized, as this corresponded to the time that studies at our institution were performed on a single machine, modeled on the study of our colleagues from Germany and USA $[19,20]$. The lumbar spine and both hips were imaged, when possible, and analyzed with the manufacturer's software. A daily calibration of the machine was done with the spine and whole body phantom and weekly calibration with the tissue bar and air scan; DXA precision determination with current staff demonstrates a coefficient of variation of $\leq 1.0 \%$ at the spine and $\leq 2.0 \%$ at the femoral neck.

Quality control assurance measurements were performed according to the manufacturer's recommendations. Positioning on the device and clothing of the patients were executed according to the manufacturer's instructions (Figure 2). Only measurements that were considered evaluable, e.g., without movement artifacts, were included in the analysis. BMD and $Z$-scores for the lumbar spine (LS), and right and left femoral neck (RFN and LFN, respectively), and total hip (TH) were recorded.

2.4. Statistical Analyses. Descriptive statistics were obtained, and the Shapiro-Wilk test was used to evaluate the normal distribution of the data. Subjects' demographic, functional, and bone density characteristics were summarized by mean (SD) for continuous variables, frequency (percentage) for nominal variables, and rates for percentage change. For group comparison, two-sample $t$-test was used for continuous variables. For gender, differences in BMD and $Z$-scores between girls and boys were evaluated. One-way ANOVA analysis with Bonferroni correction of variance was used to evaluate if there is a significant difference in BMD or $Z$ -scores among the BMI groups (underweight vs. health weight vs. overweight vs. obese) and walking ability groups. Morever, a comparison between quadriplegic and other patterns of $\mathrm{CP}$ was performed. Changes in BMD and $Z$-scores

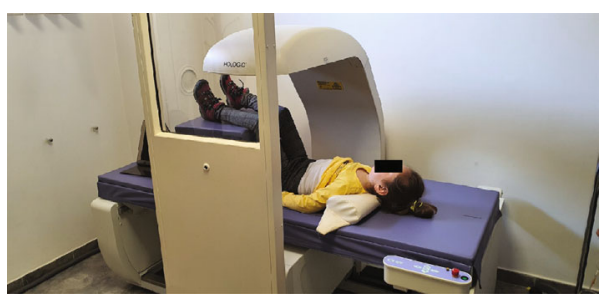

Figure 2: Positioning on the device and clothing of the patient was executed according to the manufacturer's instructions. Photographing and publishing a photograph of a child in this scientific paper is approved by the parents. The principles of the United Nations "Convention on the Rights of the Child" (UNCRC) and "Reporting guidelines to protect at-risk children" were respected. The rights to the photo are reserved by the authors.

TABle 1: Participants characteristics.

\begin{tabular}{|c|c|}
\hline & Total $(N=60)$ \\
\hline Age at first DXA, years $M$ (range) & $7.6(3.9-10.1)$ \\
\hline$\leq 11$ years-prepubertal, $N=42(\mathrm{SD})$ & $5.2(2.4)$ \\
\hline$>11$ years-pubertal, $N=18(\mathrm{SD})$ & $13.8(4.2)$ \\
\hline \multicolumn{2}{|l|}{ Sex } \\
\hline Boys, $N(\%)$ & $28(46.67)$ \\
\hline Girls, $N(\%)$ & $32(53.33)$ \\
\hline \multicolumn{2}{|l|}{ Anthropometrics } \\
\hline Weight (kg), $M(\mathrm{SD})$ & $25.4(8.1)$ \\
\hline Height (cm), $M(\mathrm{SD})$ & $125(44)$ \\
\hline $\mathrm{BMI}\left(\mathrm{kg} / \mathrm{m}^{2}\right), M(\mathrm{SD})$ & $16.6(5.6)$ \\
\hline Underweight (less than $5^{\text {th }}$ percentile), $N(\%)$ & $12(20)$ \\
\hline Healthy weight $\left(5^{\text {th }}-85^{\text {th }}\right.$ percentile $), N(\%)$ & $31(51.67)$ \\
\hline Overweight $\left(85^{\text {th }}-95^{\text {th }}\right.$ percentile $), N(\%)$ & $14(23.33)$ \\
\hline Obesity (greater than $95^{\text {th }}$ percentile), $N(\%)$ & $3(5)$ \\
\hline \multicolumn{2}{|l|}{ Walking ability } \\
\hline Complete immobility, $N(\%)$ & $41(68.33)$ \\
\hline Use of walking aids, $N(\%)$ & $10(16.67)$ \\
\hline Independent walk, $N(\%)$ & $9(15)$ \\
\hline \multicolumn{2}{|l|}{ Fracture history } \\
\hline Yes, $N(\%)$ & $14(23.33)$ \\
\hline No, $N(\%)$ & $46(76.67)$ \\
\hline
\end{tabular}

M: mean; $N$ : number; SD: standard deviation; BMI: body mass index.

was calculated only in subjects who did not receive pharmacologic treatment (beyond optimization of vitamin D and calcium intake).

\section{Results}

Demographic and medical information is presented in Table 1. The average age of children with CP when DXA analysis was first performed was about 7 years. The youngest patient was 3, and the oldest was 17 years old. Puberty, as a crucial period in the growth and maturation of children, was used to classify the children in prepubertal and pubertal 

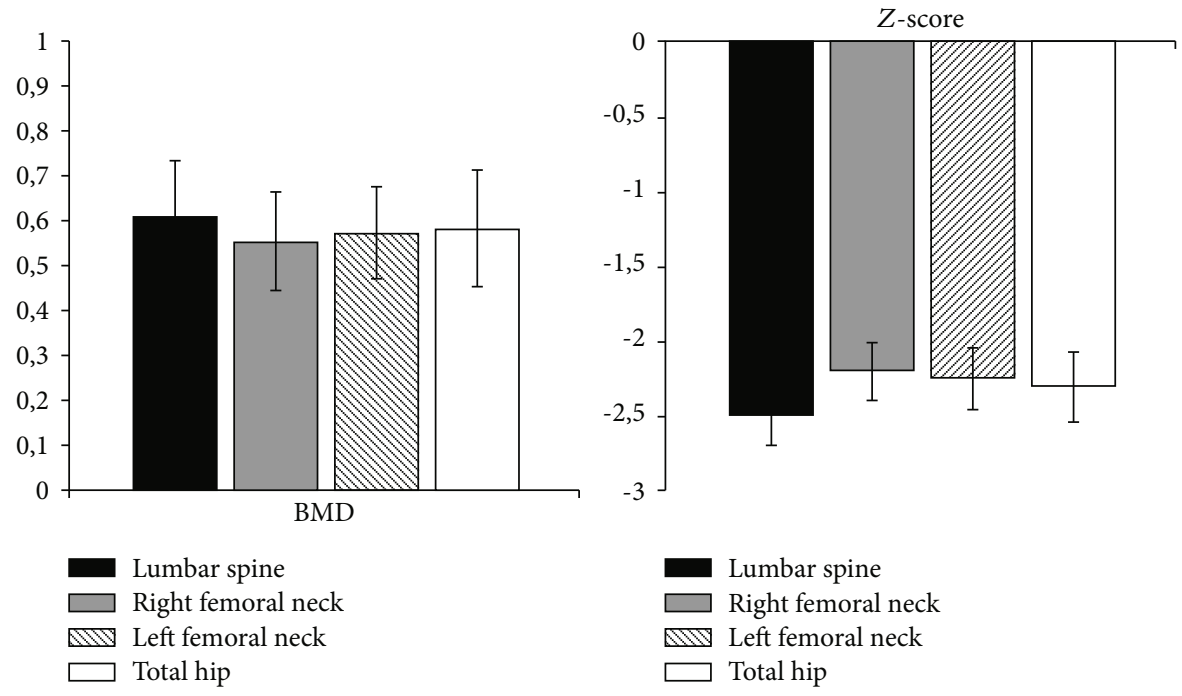

(a)
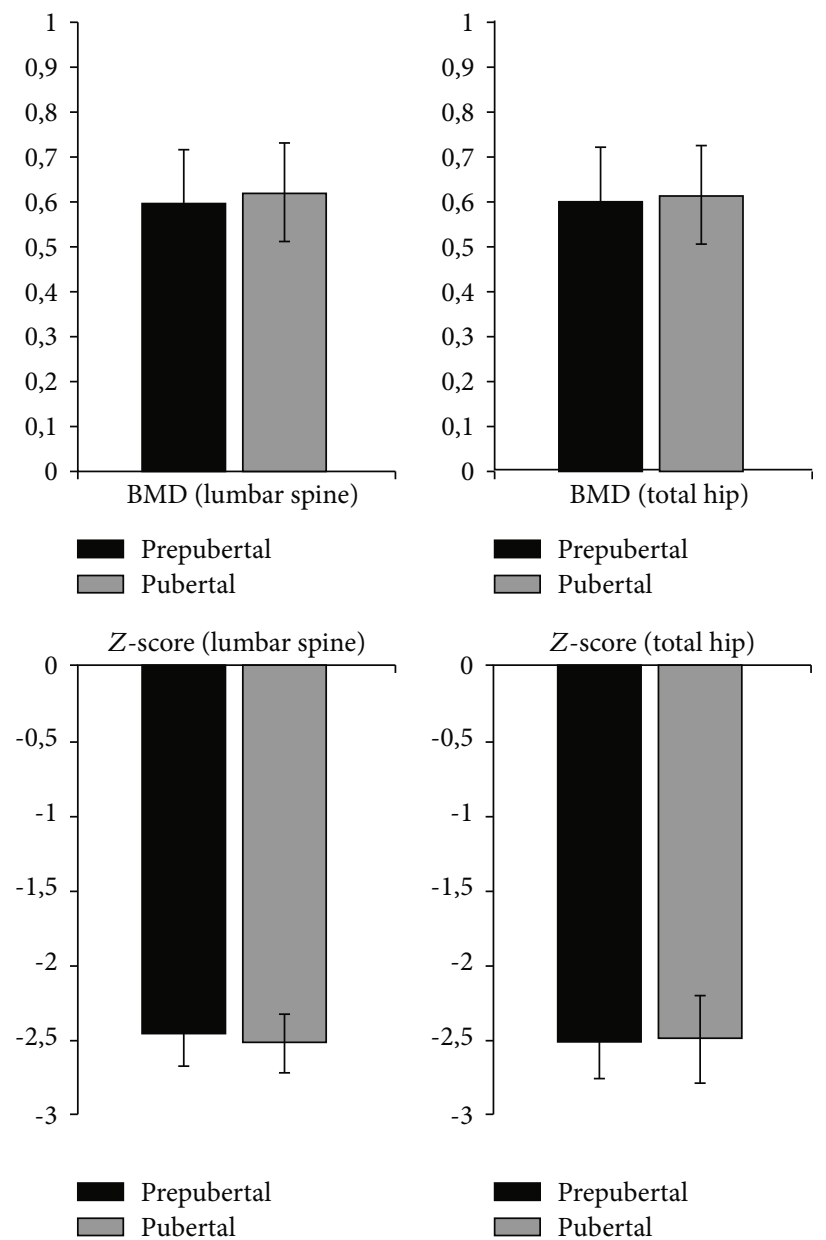

(b)

Figure 3: BMD $\left(\mathrm{g} / \mathrm{cm}^{2}\right)$ and $Z$-score of all patients (a) and in relation to puberty (b).

groups, which were then compared by their BMD and $Z$ -score values. The age of 11 years was taken as the limit [21], and there were 42 prepubertal children and 18 older than 11 years. Of the total number of children examined, there were 28 boys $(46.67 \%)$ and 32 girls (53.33\%). When it comes to anthropometric measures, the average body weight of children was about $25 \mathrm{~kg}$, height (or length in immobile patients) $125 \mathrm{~cm}$, and BMI in $51.67 \%$ of patients was normal. Overweight $\left(85^{\text {th }}-95^{\text {th }}\right.$ percentile) was present in $23.33 \%$ of the children tested, with several extreme cases, 12 

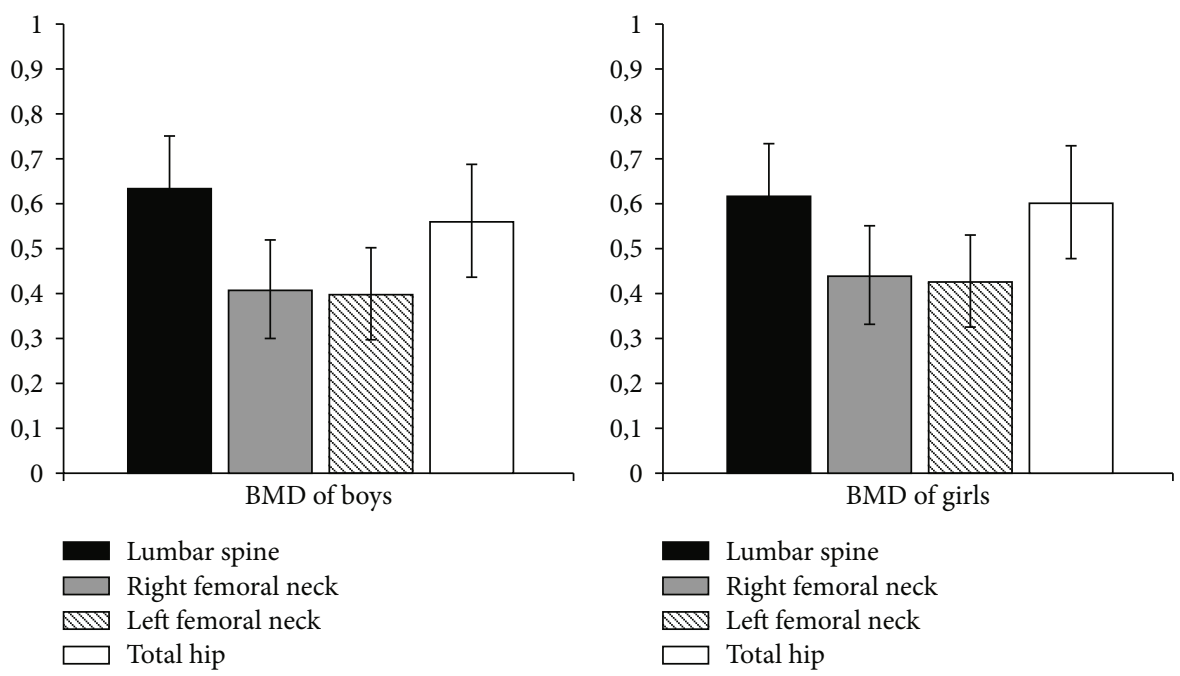

(a)
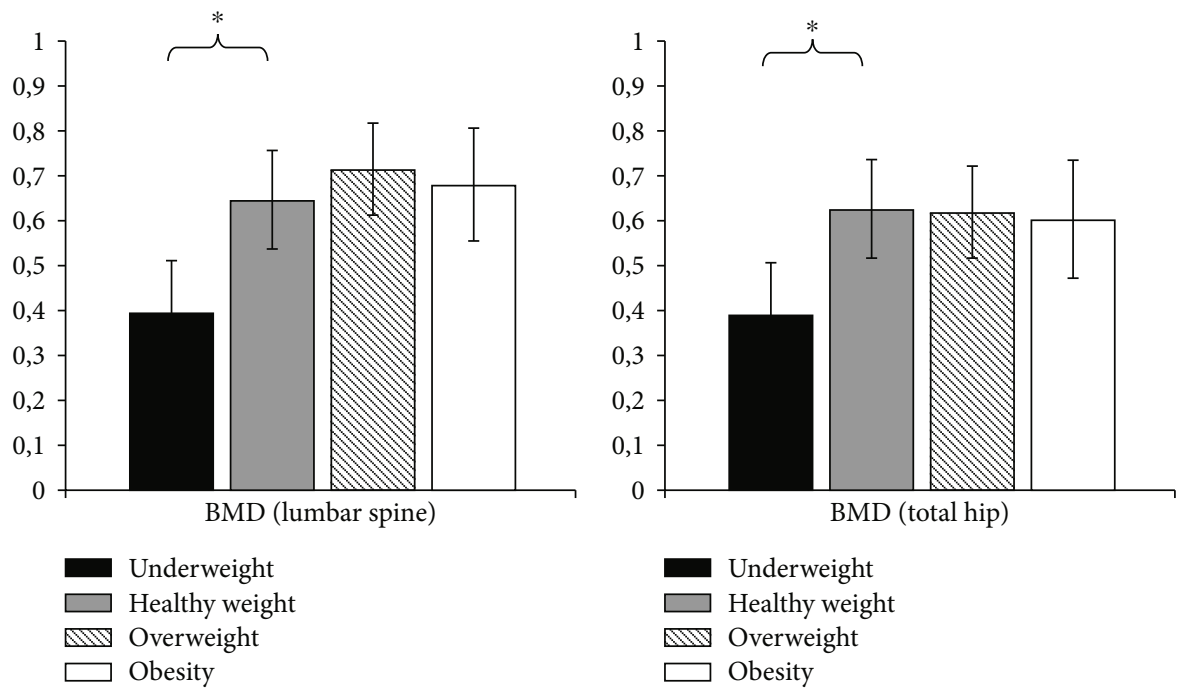

(b)
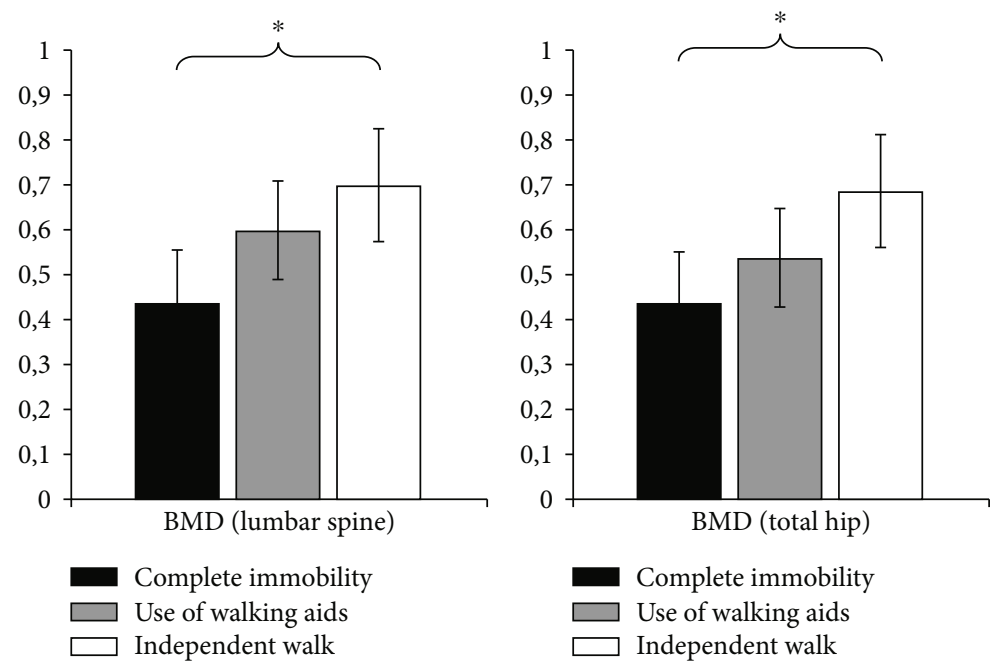

(c)

FIgUre 4: Continued. 

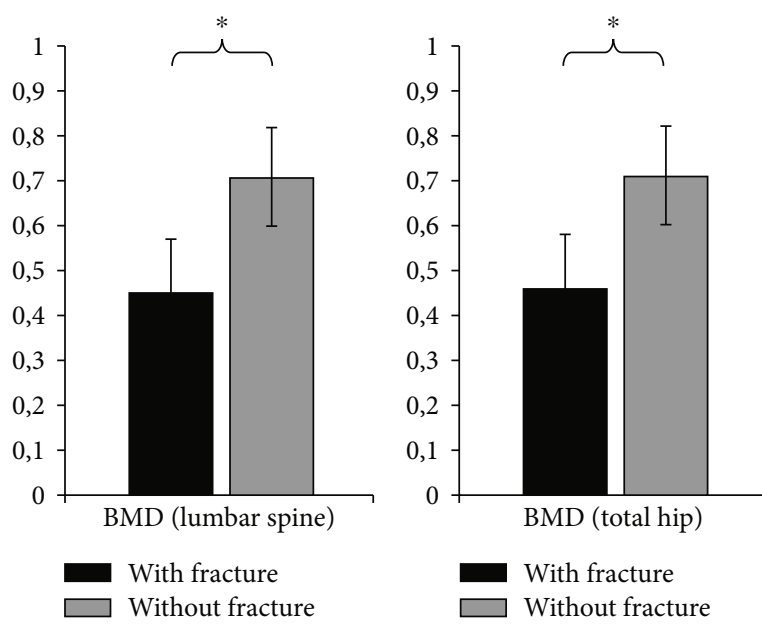

(d)

Figure 4: BMD $\left(\mathrm{g} / \mathrm{cm}^{2}\right)$ of children with CP according to patient characteristics: (a) sex, (b) weight, (c) walking ability, and (d) fracture history; ${ }^{*} p<0.05$.

underweight children (less than $5^{\text {th }}$ percentile) and 3 children with obesity (greater than $95^{\text {th }}$ percentile).

Walking ability is an important factor for proper development of the musculoskeletal system. Unfortunately, as many as $68.33 \%$ of the surveyed children did not walk, $16.67 \%$ of the children had mobility with the help of various aids, and only $15 \%$ of the respondents walked independently. There were $14(23.33 \%)$ children with a history of fracture, and $46(76.67 \%)$ had no bone fracture before or during the study (Table 1).

In our study, the BMD (mean \pm SD) at LS (LS-BMD) of all patients was $0.612 \pm 0.12$, at RFN $0.555 \pm 0.11$, at $\mathrm{LFN}$ $0.572 \pm 0.1$, and at TH (TH-BMD) $0.581 \pm 0.13$. The values of the $Z$-score (mean $\pm \mathrm{SD}$ ) at LS of all patients were -2.5 \pm 0.22 , at RFN $-2.2 \pm 0.21$, at LFN $-2.25(\mathrm{SD}=0.2)$, and at $\mathrm{TH}-2.3(\mathrm{SD}=0.23)$ (Figure $3(\mathrm{a})$ ). These values did not significantly deviate from previous literature data $(8,10,15)$. A comparison of the obtained values at LS and TH regions with respect to puberty is shown in Figure 3(b). It can be seen that there was no statistically significant difference between children in prepubertal and pubertal period (Figure 3(b)).

Likewise, a comparison of BMD with respect to gender was done. There was also no statistical significance between boys and girls (Figure 4(a)). In underweight children, LS$\operatorname{BMD}(0.388 \pm 0.12)$ was significantly lower than that in children with healthy, overweight, and obesity values $(p<0.05)$ (Figure 4(b)). Similar values were observed for the $\mathrm{TH}$ region. Complete immobility has proven to be an important parameter for BMD values. Children who were not mobile had significantly lower LS-BMD $(0.433 \pm 0.12)$ and THBMD $(0.431 \pm 0.12)$ than children who used aids or were walking independently $(p<0.05)$ (Figure $4(c)$ ). Statistical significance between the LS-BMD and TH-BMD values in children who had fractures $(0.45 \pm 0.12$ and $0.46 \pm 0.12$, respectively) and those without fractures $(0.71 \pm 0.11)$ was expected and is shown in Figure $4(\mathrm{~d})(p<0.05)$.

Analyzing the obtained values of $Z$-score against the same parameters, there was also statistical significance in patients with reduced BMI and immobility, as with those who have had fractures in the past. There was no statistically significant difference in $Z$-scores between boys and girls (Figure 5(a)-5(d)).

Finally, we compared values of BMD and $Z$-score in patients who had different clinical patterns of CP. Figure 6(a) shows that most were children with quadriplegia, as much as $56 \%$. Diplegia was present in $20 \%$ of cases, hemiplegia was $14 \%$, and triplegia was only $10 \%$. Statistical analysis showed that the BMD and $Z$-score values were lower in children with quadriplegia (LS-BMD $0.388 \pm 0.12$; $\mathrm{TH}$ BMD $0.389 \pm 0.12$; and LS-Z-score $-2.55 \pm 0.22$; TH-Zscore $-2.45 \pm 0.25$ ), compared to children with hemiplegia $(p<0.05)$, and there was no difference in comparison with triplegia and diplegia (Figure 6(b)).

\section{Discussion}

Reduction in BMD was first reported in 1994, in nine nonambulant patients with CP [22]. Several further studies have shown low BMD values in children with $\mathrm{CP}$, with results ranging from $68 \%$ to $97 \%$ of the examined children [23-27]. In our study, based on the latest recommended diagnostic criteria $[23,26,27]$, all of the examined children had osteopenia, i.e., reduced BMD, and $23.33 \%$ of them had osteoporosis. A percentage this high could be explained, by the families of the patients living in less-developed areas of our country, and that the majority of patients grew in poor conditions, which had a significant impact on nutrition and care of the children [28, 29].

In childhood and adolescence, around $50 \%$ of the complete adult bone mass is formed [30]. In a 2015 Chinese child and adolescent health study, insufficient bone mineral content (BMC) is a result of insufficient physical activity and inadequate nutrition [31]. Calcium, as the main component of BMC, is one of the most-researched nutrients related to bone health [32]. Children with CP have various difficulties breastfeeding, swallowing, and/or chewing, which reflect 

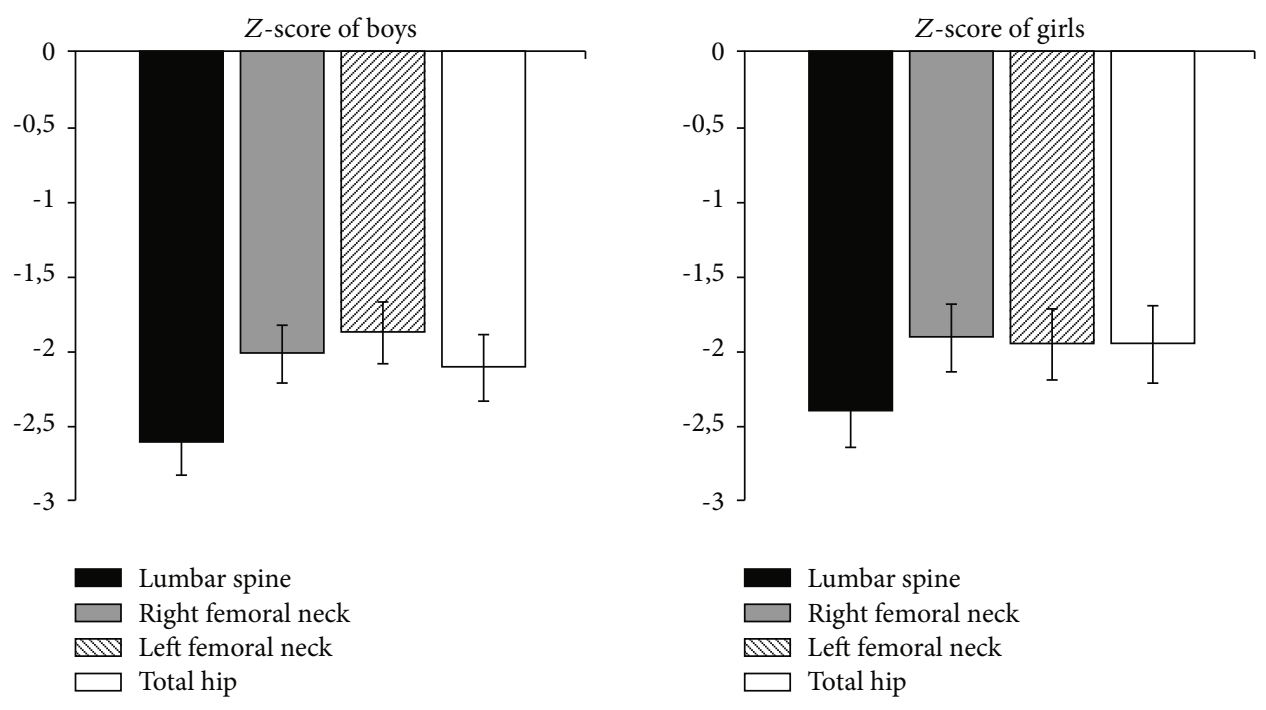

(a)
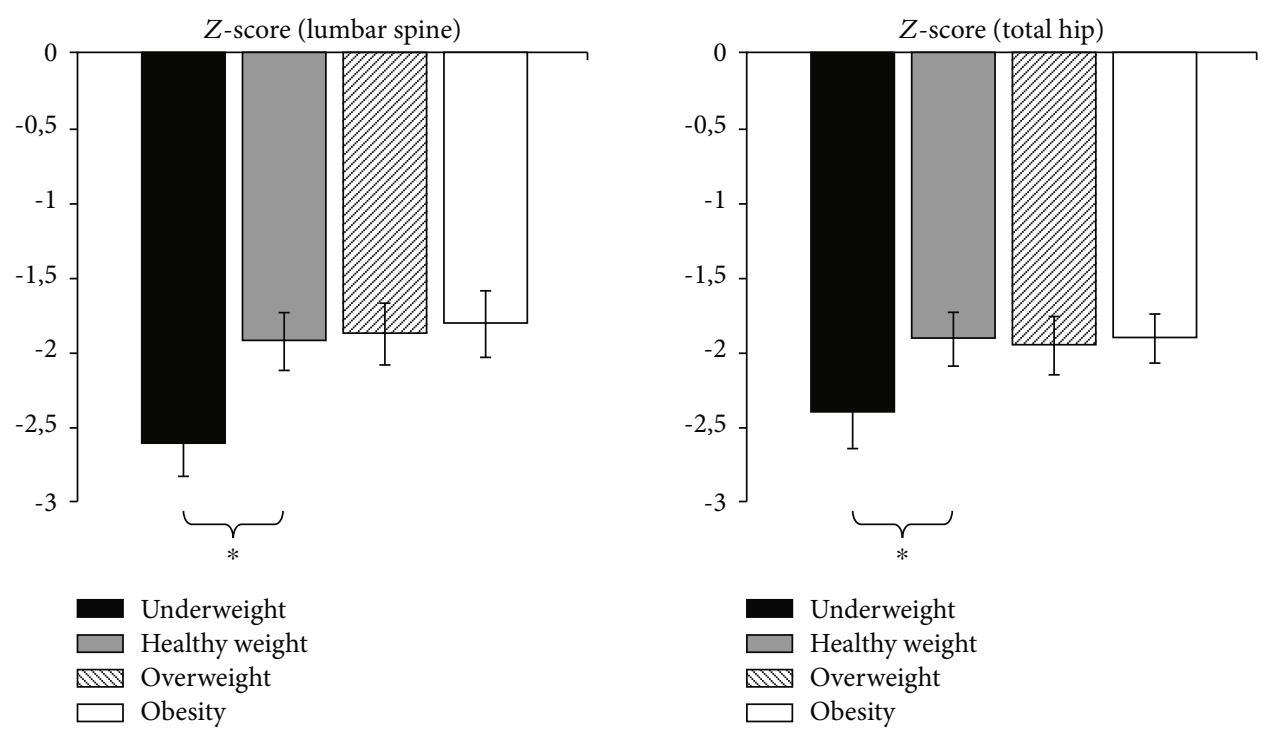

(b)
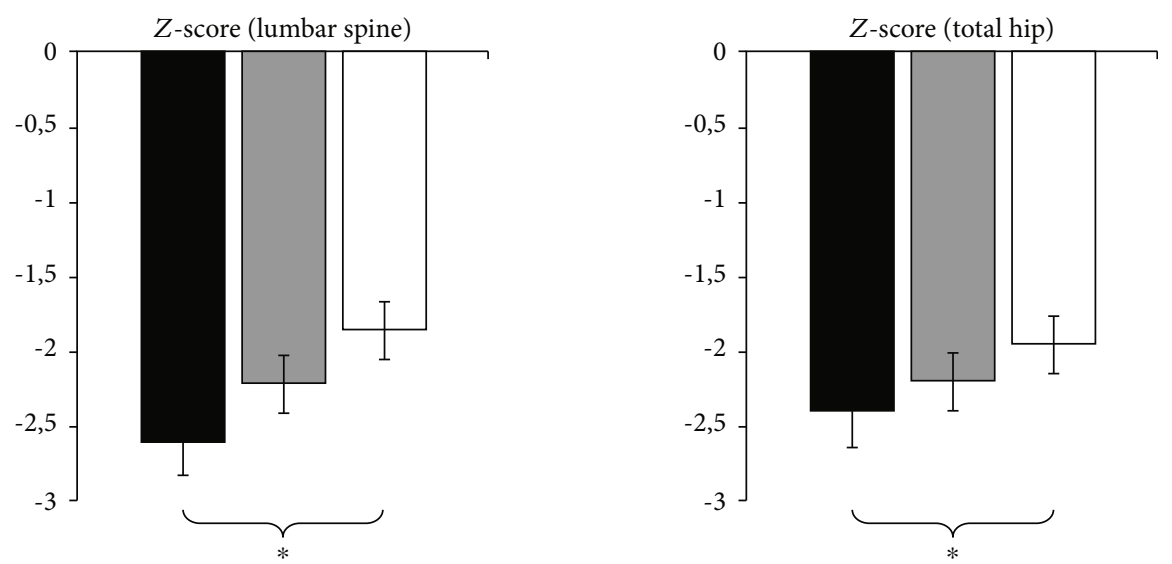

Complete immobility Use of walking aids Independent walk

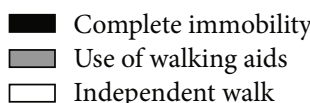

(c)

Figure 5: Continued. 


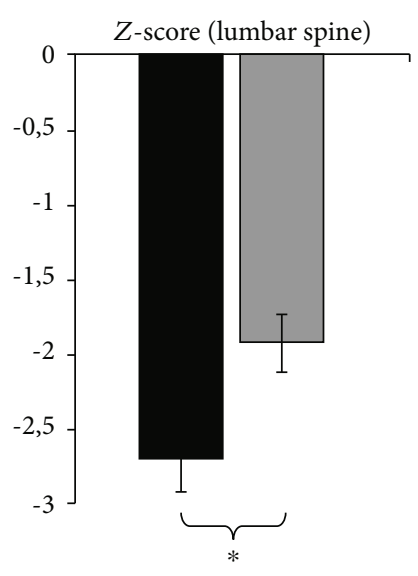

With fracture Without fracture

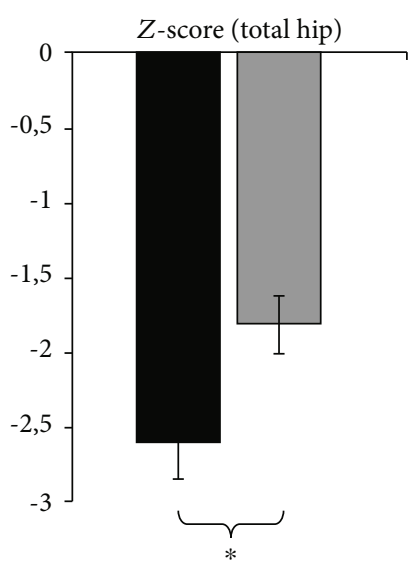

With fracture Without fracture

(d)

FIGURE 5: $Z$-score of children with CP according to patient characteristics: (a) sex, (b) weight, (c) walking ability, and (d) fracture history; ${ }^{*} p<0.05$.

itself on quality and adequate food intake and BMI. Alternative feeding methods are often used: nasogastric tube or gastrostomy [33]. Our results have shown that $20 \%$ of children had a reduced body mass and total BMI (below $5^{\text {th }}$ percentile for - underweight), which significantly affected the BMD and our results.

Increasing evidence shows that BMD is related to muscle function in healthy children [16]. Physical activity is of extreme importance when it comes to bone mass accumulation in children and adolescents, and it is observed that, in a certain degree, physical exercise can compensate for the lack of calcium intake [34]. Regular medium to high-intensity physical activity has a positive impact on bone health in young population $[35,36]$. In a recent American Physical Activity Guidelines Advisory Committee Report, it is recommended that children and adolescents, ages 6-17 years, have 60 minutes or more of medium to high-intensity physical activity on a daily basis [37]. The 2016 Chinese physical activity guideline for children recommends at least 60 minutes of mediumhigh intensity physical activity per day, as well [38]. It is noted that the degree of physical activity is in direct correlation with BMD level [27, 34], which our study confirms. Children with quadriplegia had very low values of BMD and $Z$-score, and there was a statistical significance even when compared to children with only a certain degree of motor skills. Chen et al. [16] compared the results of two studies in which the results indicate that high-level physical activity with antigravity muscle training under safety control (such as jumping under supervising and necessary support), probably produces greater bone strains $(\geq 1,500-2,500$ microstrains) or eight times the body weight in ambulatory children with CP [39, 40]. Our finding supports the hypothesis that lower motor capacity and lesser mobility existing in this group of pediatric patients can affect BMD independently of the other risk factors. In addition, weakened muscle function and lack of mechanical load, present in our patients, result in inadequate forming and modeling of the muscle tissue, which consequently leads to reduced muscular strength and abnormal bone geometry and mineral content [41]. The meta-analysis published in late 2017 shows that weightbearing exercise significantly improved the BMD in the femur compared with pretreatment values but had no effect on the BMD of the lumbar spine [42]. Mechanical stress on bone is a determinant of bone morphology, BMD, and bone strength $[42,43]$. In children with CP who have difficulties in maintaining an upright position, less mechanical force is transmitted to the femurs than the lumbar spine, because mechanical stress can be imposed on the lumbar spine in a seated position.

Low BMD is asymptomatic by itself. However, fractures that can occur cause pain and significantly contribute to the comorbidity present in this pediatric population [8]. The most common location for these is the diaphysis of long bones, e.g., the distal extremity of the femur. In our study, 14 children had fractures in their medical history, which classified them as children with osteoporosis. Considering the existing issues regarding insufficient drug efficiency and difficulties in establishing optimal dosage, as well as potential adverse reactions to drugs, pathological fractures add even more complexity to the already challenging treatment course [44].

In our study population, we found no correlation between the gender and age of children with low BMD results (Figures 3-5). On the contrary, in previous studies, it was often reported that the sex and age (prepubertal and pubertal period) were correlated with low BMD in children with CP $[45,46]$, most probably due to differences in sex hormone levels. We have no other explanation for these characteristics having no impact on BMD in our study population, except that the hormone effect (at this age) probably had not yet begun.

Taking into account the abovementioned facts, as well as the results of our study, it is clear that children with $\mathrm{CP}$ have a higher risk of low BMD, osteoporosis, and bone fractures. Children with $\mathrm{CP}$ require radiologic diagnostic procedures more often, due to the need to monitor their hip migration in order to prevent dislocation, frequent injury, and bone/joint deformities. However, exposing them 


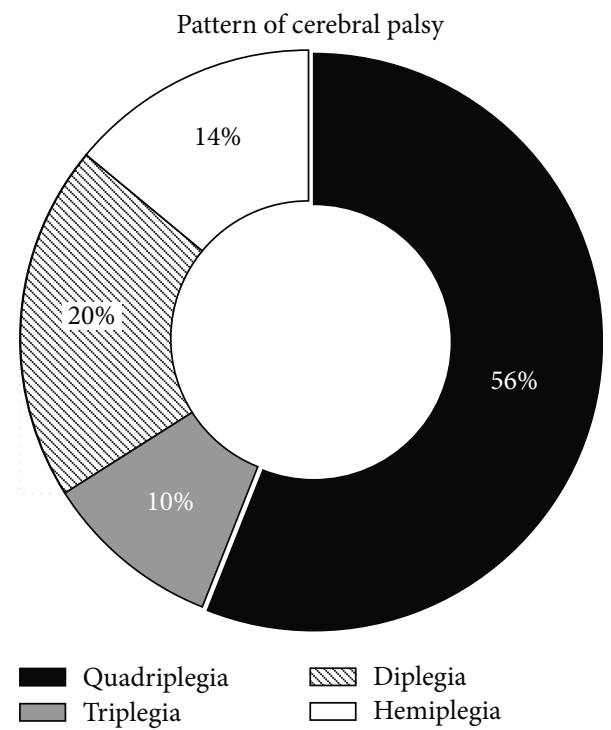

(a)
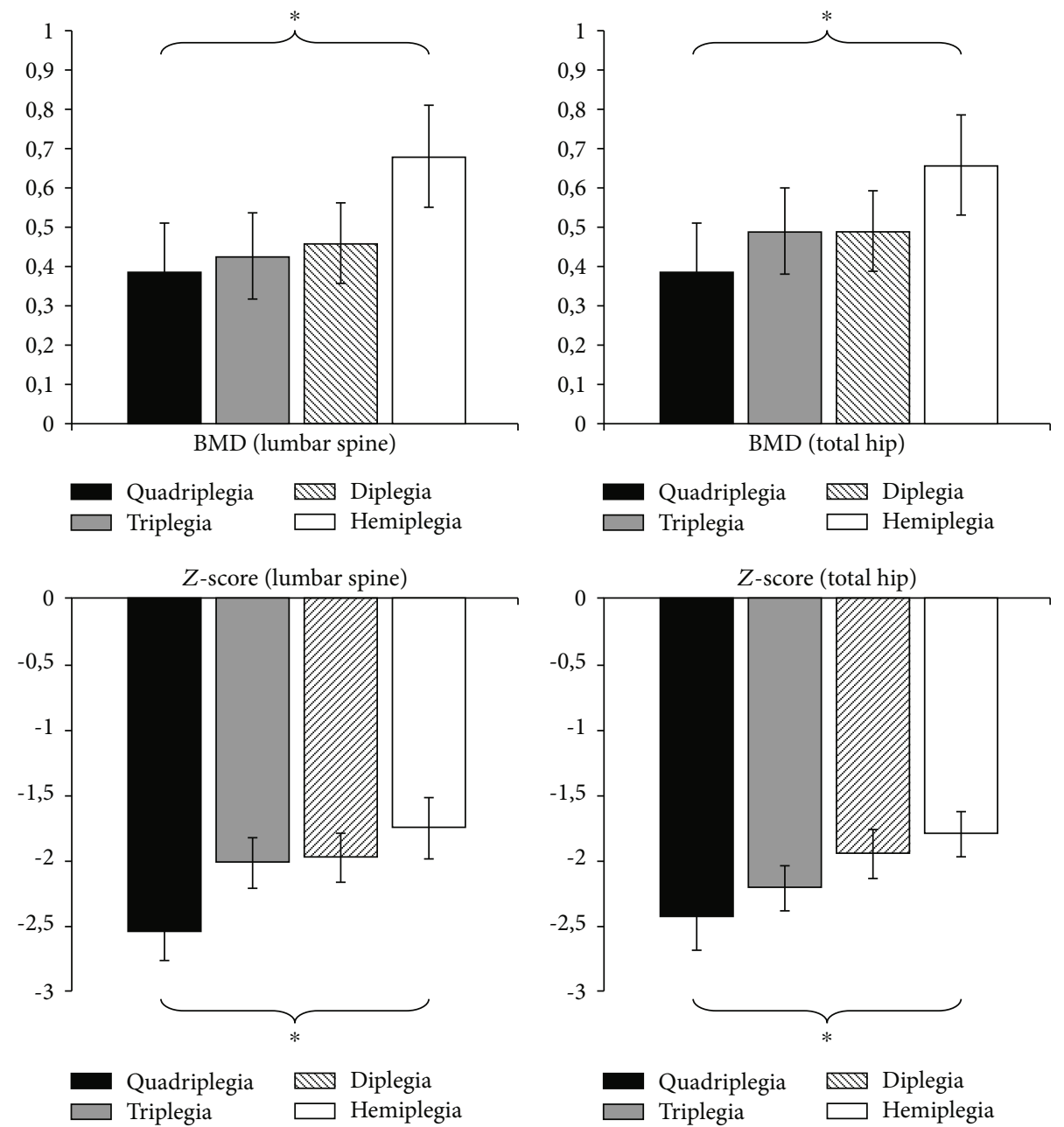

(b)

FIGURE 6: Percent of pattern of CP (a), and BMD $\left(\mathrm{g} / \mathrm{cm}^{2}\right)$ and $Z$-score of all patients and in relation to pattern of CP (b); ${ }^{*} p<0.05$. 
to additional X-radiation during nonstandard procedures, such as DXA analysis, represents an ethical question. Exposure to X-radiation carries a greater risk of malignancy, especially leukemia and thyroid cancer, in children than in adult population [47]. Previous studies have shown that many healthcare providers, including clinicians, even radiologists, are unaware of potential radiation-related risks in case of excessive and unnecessary diagnostic tests [48]. In practice, the patients often undergo tests before or without consenting to a procedure. In addition, alternative diagnostic procedures intentionally remain undiscussed. The fact that it takes the effects of the procedures 5 to 20 years to manifest them adds even more complexity to the issue [49]. Medical situations most frequently provoke multiple medical and ethical principles simultaneously and require moral and ethical judgment and commitment. Given that this study adequately and in line with the legislation of the Republic of Serbia [47] applies the ethical concept of informed consent in the pediatric patient population, the medical situation involving the diagnostic application of DXA analysis in this group of pediatric patients is ethically analysed here through the double effect phenomenon, due to the above highlighted concerns about cumulative radiation exposure in the pediatric population. The "double effect" of syntagm in medical ethics describes those practices of medical professionals that are known to have, in addition to the positive, simultaneously or successively negative consequences [50]. Led by the results of this study, which open the door to great and significant therapeutic opportunities in the field of practical prevention in this patient population, we can conclude that the benefit of this diagnostic procedure outweighs the risks of the procedure itself.

According to that, the use of DXA analysis in the pediatric population of patients with $\mathrm{CP}$ for the purpose of determining $\mathrm{BMD}$ is considered as one of those medical situations where the ethical principle of beneficence (Salus aegroti suprema lex-well-being of the patient is the supreme law) becomes more binding than the principle of no maleficence (Primum non nocere-do no harm), which were simultaneously provoked.

Its rational application in this patient population, as a positive balance of benefits and harms from it, opens the possibilities for further significant action of medical professionals who achieve the best final results for their health. It is an active action of medicine towards the prevention and reduction of the risk of further damage to health, the onset of pain and suffering, a significant deterioration in the quality of life and an additional shortening of the life expectancy of vulnerable pediatric patients with CP. Therefore, according to the result of our study, we strongly recommend this diagnostic procedure in the clinical monitoring of children with CP.

There are several limitations to our study. As in similar studies of this kind [19], the present study is a retrospective analysis of data obtained as part of a standard clinical care during an intensive rehabilitation treatment. There may be selection bias because the sample of all children with CP is not representative. In addition, anamnestic or heteroanamnestic fracture data could not be fully verified. Lower limb contractures and deformities, a common finding in children with $\mathrm{CP}$, can affect the height measurement and thus the BMI calculation in the study.

\section{Conclusion}

The present study has confirmed that CP may worsen bone health in children and adolescents. BMD and $Z$-score values in children with CP were significantly lower than the reference limits. Furthermore, BMI, walking ability, fracture history, and pattern of CP had a significant impact on BMD and $Z$ -score values of these children. All this confirms our hypothesis that CP increases the risk of bone fractures and that timely diagnosis and ensuring regular and persistent kinesiotherapy would be necessary in this pediatric population. Therefore, the use of DXA analysis outweighs the potential detrimental effect of X-radiation and we strongly recommend it in the clinical monitoring of children with CP.

\section{Data Availability}

The data that support the findings of this study are available on request from the corresponding author. The data are not publicly available due to restrictions, their containing information that could compromise the privacy of research participants.

\section{Conflicts of Interest}

All authors state that they have no conflicts of interest.

\section{References}

[1] C. Messina, G. Maffi, J. A. Vitale, F. M. Ulivieri, G. Guglielmi, and L. M. Sconfienza, "Diagnostic imaging of osteoporosis and sarcopenia: a narrative review," Quantitative Imaging in Medicine and Surgery, vol. 8, no. 1, pp. 86-99, 2018.

[2] N. S. Ma and C. M. Gordon, "Pediatric osteoporosis: where are we now?," The Journal of Pediatrics, vol. 161, no. 6, pp. $983-$ 990, 2012.

[3] E. A. Szalay and A. Cheema, "Children with spina bifida are at risk for low bone density," Clinical Orthopaedics and Related Research, vol. 469, no. 5, pp. 1253-1257, 2011.

[4] S. Stagi, L. Cavalli, C. Iurato, S. Seminara, M. L. Brandi, and M. de Martino, "Bone health in children and adolescents: the available imaging techniques," Clinical Cases in Mineral and Bone Metabolism, vol. 10, no. 3, pp. 166-171, 2013.

[5] K. W. Krigger, "Cerebral palsy: an overview," American Family Physician, vol. 73, no. 1, pp. 91-100, 2006.

[6] C. P. Panteliadis, C. Hagel, D. Karch, and K. Heinemann, "Cerebral palsy: a lifelong challenge asks for early intervention," The Open Neurology Journal, vol. 9, no. 1, pp. 45-52, 2015.

[7] J. U. Crichton, M. Mackinnon, and C. P. White, "The lifeexpectancy of persons with cerebral palsy," Developmental Medicine and Child Neurology, vol. 37, no. 7, pp. 567-576, 1995.

[8] R. C. Henderson, R. K. Lark, M. J. Gurka et al., "Bone density and metabolism in children and adolescents with moderate to severe cerebral palsy," Pediatrics, vol. 110, no. 1, p. e5, 2002.

[9] Y. Uziel, E. Zifman, and P. J. Hashkes, "Osteoporosis in children: pediatric and pediatric rheumatology perspective: a 
review," Pediatric Rheumatology Online Journal, vol. 7, no. 1, p. 16, 2009.

[10] C. M. Houlihan and R. D. Stevenson, "Bone density in cerebral palsy," Physical Medicine and Rehabilitation Clinics of North America, vol. 20, no. 3, pp. 493-508, 2009.

[11] C. F. J. Munns and C. T. Cowell, "Prevention and treatment of osteoporosis in chronically ill children," Journal of Musculoskeletal \& Neuronal Interactions, vol. 5, no. 3, pp. 262-272, 2005.

[12] R. D. Stevenson, M. Conaway, J. W. Barrington, S. L. Cuthill, G. Worley, and R. C. Henderson, "Fracture rate in children with cerebral palsy," Pediatric Rehabilitation, vol. 9, pp. 396403, 2009.

[13] Communicating radiation risks in paediatric imaging: information to support health care discussions about benefit and risk., World Health Organization, 2016, WHO website - http:// www.who.int.

[14] J. Damilakis, J. E. Adams, G. Guglielmi, and T. M. Link, "Radiation exposure in X-ray-based imaging techniques used in osteoporosis," European Radiology, vol. 20, no. 11, pp. 27072714, 2010.

[15] E. Y. Han, J. H. Choi, S. H. Kim, and S. H. Im, “The effect of weight bearing on bone mineral density and bone growth in children with cerebral palsy: a randomized controlled preliminary trial," Medicine (Baltimore), vol. 96, no. 10, p. e5896, 2017.

[16] C. L. Chen, K. C. Lin, C. Y. Wu, J. Y. Ke, C. J. Wang, and C. Y. Chen, "Relationships of muscle strength and bone mineral density in ambulatory children with cerebral palsy," Osteoporosis International, vol. 23, no. 2, pp. 715-721, 2012.

[17] J. Nurkovic, Z. Dolicanin, F. Mustafic et al., "Mesenchymal stem cells in regenerative rehabilitation," Journal of Physical Therapy Science, vol. 28, no. 6, pp. 1943-1948, 2016.

[18] Surveillance of Cerebral Palsy in Europe (SCPE), "Surveillance of cerebral palsy in Europe: a collaboration of cerebral palsy surveys and registers," Developmental Medicine and Child Neurology, vol. 42, no. 12, pp. 816-824, 2000.

[19] I. Duran, J. Katzmann, K. Martakis, C. Stark, O. Semler, and E. Schoenau, "Individualized evaluation of lumbar bone mineral density in children with cerebral palsy," Archives of Osteoporosis, vol. 13, no. 1, p. 120, 2018.

[20] C. Marciniak, J. Gabet, J. Lee, M. Ma, K. Brander, and N. Wysocki, "Osteoporosis in adults with cerebral palsy: feasibility of DXA screening and risk factors for low bone density," Osteoporosis International, vol. 27, no. 4, pp. 1477-1484, 2016.

[21] N. Brix, A. Ernst, L. L. B. Lauridsen et al., "Timing of puberty in boys and girls: a population-based study," Paediatric and Perinatal Epidemiology, vol. 33, no. 1, pp. 70-78, 2019.

[22] N. J. Shaw, C. P. White, W. D. Fraser, and L. Rosenbloom, "Osteopenia in cerebral palsy," Archives of Disease in Childhood, vol. 71, no. 3, pp. 235-238, 1994.

[23] H. Tasdemir, M. Buyukavci, F. Akcay, P. Polat, A. Yildiran, and C. Karakelleoglu, "Bone mineral density in children with cerebral palsy," Pediatrics International, vol. 43, no. 2, pp. 157-160, 2001.

[24] I. Esen, F. Demirel, A. Güven, A. Değerliyurt, and G. Köse, "Assessment of bone density in children with cerebral palsy by areal bone mineral density measurement," The Turkish Journal of Pediatrics, vol. 53, no. 6, pp. 638-644, 2011.

[25] G. Coppola, D. Fortunato, C. Mainolfi et al., "Bone mineral density in a population of children and adolescents with cere- bral palsy and mental retardation with or without epilepsy," Epilepsia, vol. 53, no. 12, pp. 2172-2177, 2012.

[26] C. Jacob Junior, I. Machado Barbosa, J. L. Batista Júnior, R. B. Leonel, L. G. Lopes Perim, and T. G. Silva Oliveira, "Assessment of bone density in patients with scoliosis neuromuscular secondary to cerebral palsy," Coluna/Columna, vol. 13, no. 3, pp. 193-195, 2014.

[27] A. Tosun, S. Erisen Karaca, T. Unuvar, Y. Yurekli, C. Yenisey, and I. K. Omurlu, "Bone mineral density and vitamin D status in children with epilepsy, cerebral palsy, and cerebral palsy with epilepsy," Child's Nervous System, vol. 33, no. 1, pp. 153-158, 2017.

[28] P. R. Fischer, T. D. Thacher, and J. M. Pettifor, "Pediatric vitamin D and calcium nutrition in developing countries," Reviews in Endocrine \& Metabolic Disorders, vol. 9, no. 3, pp. 181-192, 2008.

[29] C. G. Neumann, C. Gewa, and N. O. Bwibo, "Child nutrition in developing countries," Pediatric Annals, vol. 33, no. 10, pp. 658-674, 2004.

[30] I. M. van der Sluis and S. M. de Muinck Keizer-Schrama, "Osteoporosis in childhood: bone density of children in health and disease," Journal of Pediatric Endocrinology \& Metabolism, vol. 14, no. 7, pp. 817-832, 2001.

[31] "Chinese Association for Student nutrition \& Health Promotion Report on nutrition and health of Chinese children and adolescents 2014," Chinese Association for Student nutrition \& Health Promotion, Beijing, 2014.

[32] V. Tai, W. Leung, A. Grey, I. R. Reid, and M. J. Bolland, "Calcium intake and bone mineral density: systematic review and meta-analysis," BMJ, vol. 351, p. h4183, 2015.

[33] J. Moreno, M. Galiano, M. Valero, and M. León, “Alimentación en el paciente con parálisis cerebral," Acta Pediátrica Española, vol. 59, pp. 17-25, 2001.

[34] X. Yang, Y. Zhai, J. Zhang, J. Y. Chen, D. Liu, and W. H. Zhao, "Combined effects of physical activity and calcium on bone health in children and adolescents: a systematic review of randomized controlled trials," World Journal of Pediatrics, vol. 16, no. 4, pp. 356-365, 2020.

[35] A. Gómez-Bruton, Á. Matute-Llorente, A. González-Agüero, J. A. Casajús, and R. G. Vicente, "Plyometric exercise and bone health in children and adolescents: a systematic review," World Journal of Pediatrics, vol. 13, no. 2, pp. 112-121, 2017.

[36] S. I. Braun, Y. Kim, A. E. Jetton, M. Kang, and D. W. Morgan, "Prediction of bone mineral density and content from measures of physical activity and sedentary behavior in younger and older females," Preventive Medical Reports, vol. 2, pp. 300-305, 2015.

[37] 2018 Physical Activity Guidelines Advisory Committee. Physical activity guidelines advisory committee scientifc report, Department of Health and Human Services, Washington, DC: U.S., 2018.

[38] Y. Yang, X. Yang, F. Zhai, and Y. Cheng, "Dietary guidelines for Chinese (2016)," Journal of the Academy of Nutrition and Dietetics, vol. 116, no. 9, p. A37, 2016.

[39] H. M. Frost, "Defining osteopenias and osteoporoses: another view (with insights from a new paradigm)," Bone, vol. 20, no. 5, pp. 385-391, 1997.

[40] R. K. Fuchs, J. J. Bauer, and C. M. Snow, "Jumping improves hip and lumbar spine bone mass in prepubescent children: a randomized controlled trial," Journal of Bone and Mineral Research, vol. 16, no. 1, pp. 148-156, 2001. 
[41] N. Akhter, A. Khan, and A. Ayyub, "Motor impairment and skeletal mineralization in children with cerebral palsy," The Journal of the Pakistan Medical Association, vol. 67, no. 2, pp. 200-203, 2017.

[42] S. J. Kim, S. N. Kim, Y. N. Yang, I. S. Lee, and S. E. Koh, "Effect of weight bearing exercise to improve bone mineral density in children with cerebral palsy: a meta-analysis," Journal of Musculoskeletal \& Neuronal Interactions, vol. 17, no. 4, pp. 334-340, 2017.

[43] S. Takata and N. Yasui, "Disuse osteoporosis," The Journal of Medical Investigation, vol. 48, no. 3-4, pp. 147-156, 2001.

[44] A. M. Boyce, L. L. Tosi, and S. M. Paul, "Bisphosphonate treatment for children with disabling conditions," $P M$ \& $R$ : The Journal of Injury, Function, and Rehabilitation, vol. 6, no. 5, pp. 427-436, 2014.

[45] A. M. Boot, M. A. de Ridder, H. A. Pols, E. P. Krenning, and S. M. de Muinck Keizer-Schrama, "Bone mineral density in children and adolescents: relation to puberty, calcium intake, and physical activity," The Journal of Clinical Endocrinology and Metabolism, vol. 82, no. 1, pp. 57-62, 1997.

[46] M. Horlick, J. Thornton, J. Wang, L. S. Levine, B. Fedun, and R. N. Pierson Jr., "Bone mineral in prepubertal children: gender and ethnicity," Journal of Bone and Mineral Research, vol. 15, no. 7, pp. 1393-1397, 2000.

[47] M. S. Linet, K. P. Kim, and P. Rajaraman, "Children's exposure to diagnostic medical radiation and cancer risk: epidemiologic and dosimetric considerations," Pediatr Radiol, vol. 39, Supplement 1, pp. S4-S26, 2009.

[48] G. Alzen and G. Benz-Bohm, "Radiation protection in pediatric radiology," Deutsches Ärzteblatt International, vol. 108, no. 24, pp. 407-414, 2011.

[49] Government of Republic of Serbia, Health Protection Act, Law on Healt Care (Zakon o zdravstvenoj zaštiti), "Official Gazette of RS", no. 25/2019, Serbian.

[50] K. Turza, Medicine and Society - Introduction to Medical Ethics. Libri Medicorum, CIBID, Faculty of Medicine, University of Belgrade, Belgrade, Serbian, 2009. 